\title{
A Survey of the Threats/Impacts of Accelerating Climate Changes and Global Warming in the Light of the 2019 Report of the World Meterological Organization and Other Available Data Documenting Physical Signs of Climate Changes in Around the Global Environment and Rising Temperatures in Nigeria
}

\author{
Dr. Sylvanus, Abila \\ Senior Lecturer/Former Head of Department, Private and Property Law, Faculty of Law Niger Delta University, \\ Wilberforce Island, Bayelsa State, Nigeria
}

\begin{abstract}
This paper undertakes a survey of the threats/impacts of accelerating climate changes and global Warming highlighted in the 2019 report of the World Meteorological Organization and other available data documenting physical signs of climate changes in around the global environment and particularly the phenomena of recent rising temperatures in Nigeria.Before ending with a conclusion and a set of recommendations, the paper also examines other general perspectives and jurisprudence of climate change/global warming and associated impacts on the environment and highlighted the need for the world to act fast to avoid further devastation on the health of humanity and the global environment. .
\end{abstract}

Keywords:Survey, Threats, Impacts, Accelerating, Climate changes, Global Warming, 2019 World Meteorological Organization Report. Global Environment, Health, Humanity, Rising temperatures, Nigeria DOI: $10.7176 / \mathrm{JLPG} / 96-06$

Publication date: April $30^{\text {th }} 2020$

\section{INTRODUCTION:}

The paper commences with a summary of the 2019 World Meteorological Organisation on Accelerating Climate Change, Perspectives and Jurisprudence of Climate Change/global warming and associated impacts on the environment, the phenomena of climate change, global warming and rising temperatures in Nigeria, multidisciplinary expertise views on the current rising temperatures phenomena in Nigeria, a conclusion and recommendations.

\section{A SUMMARY OF THE 2019 WORLD METEOROLOGICAL ORGANISATION ON} ACCELERATING CLIMATE CHANGE:

Recently, the World Meteorological Organization released its statement on Global Warming for the year 2019 showing climate change as having a major effect on all aspects of the environment, as well as on the health wellbeing of the global population. The report contains data from an extensive network of partners dealing with the "physical signs of climate change such as increasing land and ocean heat, accelerating sea level rise, melting ice, the knock on effects on socio-economic development, human health, migration, displacement, food security, land and marine ecosystems"1 etc.

In the foreword to the said report written by the UN Secretary General, Antonio Guterres, it warned that the world is currently "way off track meeting either the $15^{\circ} \mathrm{c}$ or $2^{0} \mathrm{c}$ targets that the Paris agreement calls for" referring to the commitment made by the international community in 2015, to keep global average temperatures well below $2^{0} \mathrm{c}$ above pre-industrial levels. ${ }^{2}$

The report further showed that several heat records have been broken in recent years and decades. It confirmed that 2019 was the second hottest year on record and that the years, 2010-2019 was the warmest decade on record. It showed further that since the 1980 s each successive decade has been warmer than any preceding decade since 1950. The warmest year so far was 2016 but that this development could get worse. In the Words of the World Meteorological Organization, Secretary-General Petteri Taalas. "Given that greenhouse gas levels continue to increase, the warming will continue. A recent decadal forecast indicates that a new annual global temperature record is likely in the next five years. It is a matter of time"s.

Furthermore, in an interview with the United Nation's News, Mr. Taalas stated that, there was a growing understanding across societies of the World, from the finance sector to young people that climate change is the number one problem mankind is facing today, "so there are plenty of good signs that we have started moving in the right direction. Last year emissions dropped in developed countries, despite the growing economy, showing

\footnotetext{
https://public.wmo.int/en/media/press-release/wmo-confirms-2019-second-hottest-year-record visited on

Ibid. see also the Guardian Nigeria, Monday 16/3/2020 page 32

ibid 
that you can detach economic growth from emission growth. The bad news is that, in the rest of the world emissions grew last year. So, if we want to solve this problem we have to have all the countries on board. Mr. Taalas also added that countries still aren't fulfilling commitments they made at the UN Paris climate conference in 2015 leaving the world currently on course for a four to five degree temperature increase by the end of this century: "there's clearly a need for higher ambitious levels if we're serious about climate mitigation".

The Report further showed the following: "Greenhouse gas emissions continued to grow in 2019, leading to increased ocean heat, and such phenomena as rising sea levels, the altering of ocean currents, melting floating ice shelves, and dramatic changes in marine ecosystems. De-oxygenation, with negative impacts on marine life, and the wellbeing of people who depend on ocean ecosystems. At the poles, sea ice continues to decline, and glaciers shrunk yet again, for $32^{\text {nd }}$ consecutive years. Between 2002 and 2016, the green-land ice sheet lost some 260 gigatonnes of ice per year, with a peak loss of 458 gigatonnes in 2011/12. The 2019 loss of 329 gigatonnes, was well above average. In 2019, extreme weather events, some of which were unprecedented in scale, took place in many parts of the world. The monsoon season saw rainfall above the long-term average in India, Nepal, Bangladesh and Myanmar, and flooding led to the loss of some 2,200 lives in the region. Parts of South America were hit by floods in January, whilst Iran was badly affected in Late March and early April. In the US, total economic losses from flooding were estimated at around \$20 billion. Other regions suffered a severe lack of water. Australia has its driest year on record, and Southern Africa, Central America and parts of South America received abnormally low rains.in the addition to the above, the report also stated that the year 2019 also saw an above average number of tropical cyclones with 72 in the northern hemisphere, and 27 in the southern hemisphere. Some notably destructive cyclones were Idai, which caused wide-spread devastations in Mozambique and the east coast of Africa; Dorian, which hit the Bahamas and remained almost stationary for some 24 hours; and Hagibis, which caused severe flooding in Japan". 2

\section{PERSPECTIVES AND JURISPRUDENCE OF CLIMATE CHANGE/GLOBAL WARMING AND ASSOCIATED IMPACTS ON THE ENVIRONMENT:}

Before the release of the 2019 World Meteorological Organization on Accelerating Climate Change, summarised above, it is worthy to note that a large literature existed on Climate change and Global warming showing that the climate of the earth evolves and continually changes. " Several factors including; deforestation, atmospheric emissions emitting from industries and transportation infrastructures are known to contribute in no small measure to the production of aerosols which is stored in the atmosphere". The above view acknowledges the fact that technology and modern industry are, to a large extent tampering negatively with the ecology and nature.

It is important to note, on the other hand that, there is also the school of thought which opines that there is no truth in the claim that there is anything called "global warming" or "climate change" which are negatively impacting on the environment. This school of thought has described such claims as "hysteric, mere fear resulting from phony science, manmade global warming designed to mislead mankind". In the words of James Inhole, a U.S. Republican Senator (Oklahoma) for example;

With all the hysteria, all of the fear, all of the phony science, could it be that manmade global warming is the greatest hoax ever perpetrated on the American people

Opinions of this school of thought have also described concepts of global warming and climate change as theories developed by "all the players-from politicians and scientist to big corporations and [that] the UN benefit from instilling fear into billions of human beings over unproven theory of manmade global warming." 6 This school of thought has also been cited as the basis upon which "Andrei Illarionov, Vladimir Putin's economic adviser to describe Kyoto Protocol on climate change as scientifically unfounded nonsense, to be likened to fascism, and that the decision by Russia to adopt the protocol was purely political".?

Without much ado, however, it is submitted that the phenomena of climate change and global warming, presently constitute one of the major problems facing mankind specifically and the global environment generally and except confronted headlong/timeously the survival of man and ecosystems planet is put in jeopardy in both the developed and the developing countries. It would appear that the impact of global warming change are likely to impact more negatively in the developing nations. James Lovelock, a distinguished scholar and scientist has warned in his work entitled "global warming too far gone" as follows.

Our global furnace is out of control. By 2020, 2025, you will be able to sail a sailboat

\footnotetext{
${ }^{1}$ ibid

2 ibid

${ }^{3}$ Ibid

${ }^{4}$ Federal Republic of Nigeria (Nov. 2003) 50 Nigeria's First National Communication, under the UN framework convention on climate change

${ }^{5}$ James Inhole, The Science of Climate Change: “A Speech delivered to the U.S Senate Committee on Environment and public works, July 28 , 2003.'

${ }^{6}$ World Net Daily, March 1, 2007

${ }^{7} \mathrm{Http} / / /$ Putinru. Com/news item/3/072html.
} 
to the North Pole. The Amazon will become a desert, and the forest of Siberia will burn and release more methane and plagues will return. . . There is no realization of how quickly and irreversibly the planet is changing. ... Maybe 200 million people will migrate close to the Arctic and survive this. Even if we took extraordinary steps, it would take the work! 1,000 years to recover. ${ }^{1}$ "

An earlier report published by the inter-governmental panel on climate change (i.e. the IPCCS) $4^{\text {th }}$ Assessment Report found out that the issues of global warming and climate change were "unequivocal". Similar reports such as the Stern review sponsored by the Government of Britain on the climate change economics ${ }^{2}$ have verified the need for urgent global response to the threats of global warming and climate change. Other global events ranging from the unprecedented 2012 floods in Nigeria and the Philippians unprecedently high ice melts in Arctic, the now well-known decline in the Great Barrier Reef in Australia and high incidences of extreme drought in the United States of America and the current rising temperatures in Nigeria give credence to the assertion that climate change and global warming are real. ${ }^{3}$

The above events and others eloquently give credence to the fears that if the issues of climate change and global warming are not properly handled, the negative consequence of the phenomena will increase the incidences of wild fires, accelerated heat waves and coastal erosion will bring about a decrease in the quantity of air being taken by mankind and so many other negative consequences examined below in this paper. ${ }^{4}$ There are predictions that these and other impacts of global warming and climate change will drastically affect the social, economic and healthy leaving of both local communities and the global environment ${ }^{5}$ with more catastrophic effects on the under developed and developing Nations of the world. ${ }^{6}$

That the above enumerated threats are real has since been validated by other occurrences such as the intensely rising heat waves in Nigeria, droughts in America the melt offs of Ice in the United States of America, the continuing ice melt incidences in greenland and other negative occurrences in the environmental conditions in the different nations of the world, over the years. These and other negative occurrences in the global environments have led to the development of legal frameworks, around the globe, to forestall the increasing threats of climate change and global warming in several nations of the world to wit: United Kingdom, France, Russia, the United States, Canada, Japan, Germany, the G8 Nations and India, China and Brazil and the national academics to jointly endorse the report of the Inter-Governmental Panel on Climate Change (i.e. the IPCCS) $4^{\text {th }}$ Assessment Report which affirmed the threats posed by climate change and global warming and stressed the need for urgent action. Consequent upon the above, many nations of the world are taking positive action to contain the scourge of climate change and global warming. ${ }^{7}$

It is instructive to note the United Nations framework on climate change applies the term "climate variability" to describe the background variations not linked with human activity as in variations with global climate. ${ }^{8}$ This is perhaps, why Louka, E. in his book entitled "International Environmental Law: Fairness, effectiveness and world order", submitted that the concept of climate change revolves around the change in the atmospheric temperature of the earth due to the effect of various pollutants especially carbon dioxide which are emitted. ${ }^{9}$

Other experts have also issued warnings to the effect that the planet, Earth is currently facing an 'imminent peril" and sitting, as it were on the princents of a catastrophic rising temperatures or heating and will unleash irreversible negative consequences on future generations. ${ }^{10}$ The above and related warnings are hinged on other scientific research findings that the persistent pollution of carbon-dioxide will bring about ${ }^{11}$ a planet that is

\footnotetext{
${ }^{1}$ James Inhole, The Science of Climate change.' A Speech delivered to the U.S Senate Committee on Environment and public works, July 28, 2003.

${ }^{2}$ Ibid

${ }^{3}$ Ibid.

${ }^{4}$ Lovclock,J., 'Global Warming Too Far Gone' The Independent, 5th September, 2006. Sec also: 'A Conversation with James E. Lovelock: Updating Prescriptions for Avoiding Worldwide Catastrophe’ The New York Times 12th September 2006. In the 1950s Lovelock designed technology that enabled Rachel Carson to measure and expose the danger of pesticides. Later, after making an expedition to the Antarctic, he helped prove that CFCs, human-made chemicals, were damaging the ozone layer. Flis 'Gaia' theory, once dismissed by traditional biologists as heresy, can now fairly be said to have transformed scientific understanding of the Earth, to that of self- regulating system balanced to allow life to flourish. Lovelock's predictions are based on measurements of atmospheric gases, ocean temperatures, tropical and arboreal forests, permafrost and the cryosphere.

${ }^{5}$ Intergovernmental Panel oil Climate Change (IPCC), available at http://www.ipcc.ch/ Accessed 2/02/2013 This website contains links to many different types of documents prepared by IPCC. The site contains reports outlining scientific findings, reports prepared for the COPs, speeches and presentations.

${ }^{6}$ Available at http: II webarchive. National archives. gov. uk I + I http: I www. hrn -treasury. gov. uk I sternreviewindex.htm Accessed 2/0212013.

${ }^{7} \mathrm{http}: / /$ www.aljazeeracomiindeptWopinion/

${ }^{8}$ Intergovernmental Panel on Climate Change, 'Climate Change 2007: The Physical Science Basis Summary for Policymakers', available at http:llwww.ipcc.chl Accessed 2/0212013. See also Massachusetts v. EPA, 127 5. Ct. 1438, 1455 (2007) (lawsuit seeking to compel federal regulation of automotive emissions)

${ }^{9}$ Ibid

${ }^{10}$ Ibid.

${ }^{11}$ Eilperin, J., 'Military Sharpens Focus on Climate Change', WASHINGTON POST, $1{ }^{\text {st }}$ April, 2007.
} 
"transformed and on a completely obliterated earth which will lose its prominent fixtures such as the amazon forest, the coral reefs, the Greenland and the polaric sheets and others stated by Pearce, in his work: "With Speed and Violence" why scientists fear tipping points in climate change ${ }^{1}$.

On a final note reference is hereby made also to the following other researched scientific findings which paint gloomy pictures on the negative impact of climate change and global warming around the globe environment:

1. There exists a delicate radiation interaction coming directly from the atmosphere of the earth that of the sun. ${ }^{2}$

2. The temperature of the earth is to a large extent affected by the existence of many pollutants which are interminable and interact. ${ }^{3}$

3. The atmosphere contains oxygen, ozone gas, nitrogen etc. and other greenhouse gases to wit: methane, nitro oxide, carbon dioxide and chloro-flurocarbons (CFC). ${ }^{4}$

4 Radiations of the solar have been established, moving at the frequencies of light passing through massively through the atmosphere to cause the warming of the plenary surface emitting energy at the "lower frequencies of the infracted thermal radiations". 5

5. Infracted radiations are absorbed by greenhouse gasses which also radiate energy to the surface and lower atmosphere. $^{6}$

6. The greenhouse effect to which the climate change is attributed is a natural phenomenon... ${ }^{7}$

7 There is a process which makes the atmospheric and the surface of the earth to absorb some part of the radiation from the sun which also reflects back into space the remainder of the radiation. ${ }^{8}$

8. The greenhouse gases play the very significant role of ensuring the trapping of the radiation in the "lower levels of the atmosphere of the earth. ${ }^{9}$ The above explained process is technically referred to as the greenhouse effect "without which the earth would be as cold as the moon. ${ }^{10}$ This phenomenon has been described by the Intergovernmental Panel on Climate Change ( $4^{\text {th }}$ Assembly report as "unequivocal".

10. Flowing from the above it naturally follows that when even there is an increase of greenhouse gases in the atmosphere, as it is presently, there is corresponding in the "greenhouse effect and changes in the climate of the Earth. ${ }^{11}$

11. The current problems of climate change and global warming are traceable to the fact that there is an increase in the anthropogenic source of greenhouse gases which are producing the effect of disestablishing the natural balance between the emission of greenhouse gases and their sinks (e.g. forests) - which has led considerably to climate change and global warming in the nations of the world. ${ }^{12}$

12. Other relatively recent data from scientific studies have also shown drastic changes in temperature, rainfalls, floods etc. These data seem to produce evidence pointing to the fact that over the $20^{\text {th }}$ century, the average world temperatures would rise above normal natural levels.

It is now necessary to examine the phenomena of rising temperatures in Nigeria, their impact on humanity, the Nigerian environment particularly and the global environment generally.

\section{THE PHENOMENA OF CLIMATE CHANGE, GLOBAL WARMING RISING TEMPERATURES IN NIGERIA}

In recent times, cases of natural disaster in the form of floods and fire outbreaks have wreaked havoc across Nigeria. "This has resulted in the loss of lives and damage to property worth millions of naira. The global effect of climate change, rapid urbanization and increased economic activities contribute to the frequent cases recorded across the

\footnotetext{
${ }^{1}$ Pearce, F., With Speed and Violence: Why Scientists Fear Tipping Points in Climate Change, (Beacon Press 2007), p. 10

${ }^{2}$ Louka, E., International Environmental Law: Fairness, Effectiveness, and World Order, (Cambridge: Cambridge University Press, 2006), p. 356.

${ }^{3}$ Hausen, J, 'Climate Change and Trace Gases', PHIL. TRANS. R. SOC. A, (2007) p. 1925, available at http://www.planetwork. Net/climate Hansen 2007.pdf. Accessed 2/02/2013. See also Connor, S., 'The Earth Today Stands in Imminent Peril', THE INDEPENDENT June 19, 2007, available at http://environment. Independent.co. uk/climate change/article2675747ece. Accessed 2/02/2013.

${ }^{4}$ Intergovernmental Panel on Climate Change, 'Climate Change 2007: The Physical Science Basis Summary for Policymakers', available at http:llwww.ipcc.chl Accessed 2/0212013. See also Massachusetts v. EPA, 127 5. Ct. 1438, 1455 (2007) (lawsuit seeking to compel federal regulation of automotive emissions).

${ }^{5}$ Ibid.

${ }^{6}$ Ibid.

7 Eilperin, J., 'Military Sharpens Focus on Climate Change', WASHINGTON POST, $1^{\text {st }}$ April, 2007.

${ }^{8}$ Engel, K. H. Saleska, S. R., 'Subglobal Regulation of the Global Commons: The case of Climate Change', 32 ECOLOGY L.Q. (2005), p. 183; DeShazo JR., DeShazo , J. R., Freeman, J.' Timing and Form of Federal Regulation: The Case of Climate Change', 55 U. PA I. R1V. (2007) pp.1499, 1521-29.

${ }^{9}$ Ibid.

${ }^{10}$ UNFCCC, supra

${ }^{11}$ Louka, E., International Environmental Law: Fairness, Effectiveness, and World Order, (Cambridge: Cambridge University Press, 2006), p. 356.

${ }^{12}$ Hausen, J, 'Climate Change and Trace Gases' , PHIL. TRANS. R. SOC. A, (2007) p. 1925, available at http://www.planetwork. net/climatel Hansen 2007.pdf. Accessed 2/02/2013. See also Connor, S., 'The Earth Today Stands in Imminent Peril', THE INDEPENDENT June 19, 2007, available at http://environment. independent.co. uk/climate change/article2675747ece. Accessed 2/02/2013
} 
country.",

Closely related to the summary of the 2019 world Meteorological Organization on Accelerating Climate Change, examined earlier in this paper and its correlations with the concepts of climate change and global warming, it is important to state that between the month of January 2020 till the writing of this paper, Nigerians have being crying out for the unbearable heat of the day and night. ${ }^{2}$ Due to the current hot and humid weather nationwide, even in coastal areas, such as Lagos. ${ }^{3}$ There are persistence complaints in the last couple of weeks over the rising temperatures which have progressed to 40 degrees and even higher in many parts of Nigeria. ${ }^{4}$ Indeed, the situation is causing concern across the country as meteorologists and medical experts have warned of the dangers on human and natural resources. Generally speaking, the temperatures in Nigeria currently, are about an average of 33 degree Celsius and 70 percent humidity in Lagos to 39 degree Celsius and 11 per cent in Maiduguri. Complaints are rife about people sweating excessively and that heat rashes have become regular each day. There are wide reports that children can no longer sleep well at night, making it difficult for many, especially children, to sleep comfortably at night. ${ }^{5}$

\section{MULTI-DISCIPLINARY EXPERTISE VIEWS ON THE CURRENT RISING TEMPERATURES PHENOMENA IN NIGERIA}

Several views have being expressed across several professional lines/lenses on the causes and negative consequences of the current rising temperatures phenomena in Nigeria. The Nigerian Meteorological Agency has warned Nigerians to prepare for hotter nights and days and called for strategic preparations and be ready to participate in climate resilient practices to deal with likely damages arising from the rising temperatures. By reason of the heat waves on human beings which may cause "dehydration that can lead to unconsciousness or death, chicken pox, heat rashes, and psychological stress. According to some experts, the rising temperatures are due to the heat waves resulting from the emission of greenhouse gases". ${ }^{6}$ Warnings, have also, come from Medical experts that the rising temperature may lead to more serious consequences, including excessive bleeding and skin cancers, kidney failures, strokes, etc. While some scientists have blamed the rising temperatures on increased ultra violet (UV) rays caused by the depletion of the ozone layer, meteorologists, have, also explained that the rising temperature "is a normal phenomenon around this period of the year due to transition from dry to rainy season". "According to a research review, an increase in heat waves worldwide linked to climate change might be behind the epidemics of kidney diseases detected in workers, who are increasingly exposed to heat and dehydration"? According to a Public Physician: Prof Akin Osibogun, at the Lagos University Teaching Hospital (LUTH), IdiAraba, in Nigeria:

"when the weather is persistently hot and humid, as being experienced now, what happens is that there will be heat exhaustion and hydration. When this loss of bodily fluid continues without adequate replacement, it will affect the body organs, especially the kidney that is involved with ultra-fraction. This can lead to kidney failure. Rapid water loss, causes the kidney's functioning to slow down, resulting in temporary or permanent kidney failure",

Professor Akin Osibogun further submitted that:

"Extreme heat causes rapid water loss, resulting in acute electrolyte imbalance. The kidney, unable to cope with the water loss, atinine and other toxins from the body. Coupled with a lack of consistent water intake and this brings about permanent or temporary kidney failure. Another thing that can happen under this kind of hot and humid weather is that it will affect the brain and blood. It makes the blood less viscous and can easily escape from the vessels, causing excessive bleeding and haemorrhagic stroke. ${ }^{8}$

Another strong view is to the effect that global warming and rising temperatures "can also cause skin cancer (in albinos) ... People with black (dark) skin are protected from the carcinogenic effect of direct ultra-violet rays from the sun, because their skins have melanin. In most cases, they develop rashes, which can be very discomforting." 9 A supporting view is also found in another study published in the Asian Journal of Pharmaceutical and Clinical Research which discovered that "the burden of renal diseases might increase, as the period of hot weather becomes more frequent, and this is further aggravated in advanced ages and people with

\footnotetext{
See the Guardian, Nigeria, Thursday, March 26, 2020.

See the Guardian, Nigeria, Saturday, February 29, 2020 p. 11, 31, See also the Guardian, Sunday, March 1, 2020 p.13

Ibid

Ibid

Ibid

Ibid

The Guardian Saturday, February 29, 2020 p.11.

Ibid

${ }^{9}$ Ibid
} 
chronic diseases, such as diabetes and hypertension". ${ }^{1}$ Similarly a study carried out by the Clinical Journal of the America Society of Nephrology, also, discovered "that extreme heat exposure could have immediate health effects, causing dehydration, heat exhaustion and heat stroke, as well as worsening pre-existing chronic disease, which can be fatal". ${ }^{2}$ The society further found out that though "chronic kidney disease is often caused by diabetes or high blood pressure, and could also be the result of recurrent heat exposure with physical activity and not enough hydration, which puts a heavy strain on the kidneys". There is further support for the above by a recent discovery that people "really do get hot and bothered in warm weather". This study further found out that stress hormones rise in tandem with the thermometer. "The discovery sheds fresh light on a phenomenon that has puzzled scientists for years sometimes dubbed the 'summer times blues' as the weight of evidence from other research findings showing that there exists a link between heat exposure to aggression, suicide and violence. This has been further confirmed by a group of Polish researchers". 4

Relatedly, further confirmation is found in the Daily Matluk, ${ }^{5}$ which pointed to the fact that rising temperatures have negatively implications for public health. This report was said to have been first highlighted by Dr. Dominika Kanikowska, a pathophysiologist at Pozman University of medical Sciences, who pointed out that having "more circulating when it is warm was a surprise. According to the pathophysiologist: "these Non-intuitive findings contradict traditional concepts of the taxing physical toll of winter and the relaxed ease of summer." While it is well known that the original data that first associated heat with hostility came from crime statistics, there is now sufficient analyses showing that, the number of peoples getting involved in violence "increased in summer - especially when it was warmer than average". ${ }^{7}$

There are also numerous theories that have been submitted, amongst other things that "raised temperatures" cause increase in heart rate, testosterone and other metabolic reactions that trigger the sympathetic nervous system and that same is responsible for the fight-or-flight response- so people are more inclined to flight. Kanikowska and colleagues justified the above decision with the explanation that there is a strong relationship between hot weather and cortisol which is also referred to as the 'stress hormones' because same are released into the bloodstream during difficult or upsetting situations. Kanikowska further observed that: "The hormone helps reduce inflammation and is essential for maintaining overall health. Cortisol levels are typically highest in the morning and gradually drop throughout the day. Levels are lower in the evening to maintain healthy sleeping patterns. ${ }^{8}$ Illness, lack of sleep and certain medications can affect cortisol levels more than normal daily fluctuations." Kanikowska's research study group carried out on female medical students on two separate days in both winter and summer found the cortisol levels to be higher on the latter dates. ${ }^{9}$ There is also evidence from a new research which suggests that drinking sugary, caffeinated soft drinks while exercising in hot weather may increase the risk of kidney diseases. The study which has been published ahead of print in the American Journal of physiologyRegulatory, Integrative and Comparative physiology. ${ }^{10}$ A research team from the University at Buffalo in New York $^{11}$ also conducted a study on healthy adults in a laboratory environment that mimicked working at an agricultural site on a hot day of 95 degrees. The volunteers were made to complete an hour-long exercise cycle consisting of a 30-minute treadmill workout which was followed by three different five-minute lifting dexterity and sledgehammer swinging activities. After 45 minutes of exercise, the volunteers were made to rest for 15 minutes in the same room while drinking 16 ounces of either a high fructose, caffeinated soft drink or water. After the break, they repeated the cycle three more times for a total of four hours. Before leaving the laboratory, the volunteers were given more of their assigned beverage to drink before consuming any further fluids. The volume was either 1 liter or a volume equal to 115 percent of their body weight lost through sweating, if that amount was greater. The researchers measured the participants' core body temperature, heart rate, blood pressure, body weight and markers of kidney injury before, immediately after and 24 hours after each trial. All volunteers participated in both soft drink and water trails separated by at least seven days.

Also, according to the study. ${ }^{12}$ titled "Investigating Effects of Climate Change on Health Risks in Nigeria"

\footnotetext{
${ }^{1}$ see 87 Journal of Academic Science academic, at www.innovareaccessed 3/3/2020 See also Guardian, Ibid

${ }^{2}$ Clinical journal of the America Society of Nephrology (see CJASN Vol. 15, Issue 2 February 07, 2020 accessed 3/3/2020 see also Guardian, Ibid.

${ }^{3}$ Ibid

${ }^{4}$ Ibid

${ }^{5}$ see journal of cell science (116 pt16):3277-84 September 2003 accessed 3/03/2020.

${ }^{6}$ Guardian, ibid see ISSN: 0239-9415 http://www.zeszyty.fem.put.poznan,pl accessed 3/03/2020)

7 Guardian, ibid

8 Ibid

${ }^{9}$ See Guardian, Ibid. see also American physiological society meeting in San Diego the-app.org accessed 3/03/2020.

${ }^{10}$ See Guardian, Ibid. see also American Journal of physiology-Regulatory, Integrative and Comparative physiology. (see ISSN 15221490 , $03636119 \mathrm{http}: / /$ www.scimagojr.com accessed on 3/03/2020)

11 See Guardian, Ibid. see also University at Buffalo in New York (see U.S. News \& world report- best law school. Retrieved 25 January 2019 accessed on 3/03/2020)

${ }^{12}$ Titled "Investigating Effects of Climate Change on Health Risks in Nigeria" and Published in ONLINE FIRST by Ilevbare Femi See Guardian, Ibid.
} 
and published first online by Ilevbare Femi, confirmed the fact that cerebra-spinal meningitis is one of the infectious diseases likely to be caused by climate change and further that incidences of meningitis, for instance, have been on the rise in Nigeria due to the excessive heat. According to Akingbade, cases of meningitis have been reported to increase in Nigeria as a result of excessive heat.

\section{CONCLUSION}

This paper undertook a multi-disciplinary analyses of the impacts of climate Change and global warming in Nigeria and around the global environment in the light of the 2019 report of the World Meteorological Organization and other available data documenting physical signs of climate changes in around the global environment and the abnormal rising temperatures, in recent times in Nigeria and likely adverse negative impacts on the health of the peoples/the environment of Nigeria and similar consequences on the globe resulting from climate change and global warming. The paper analyzed the phenomena of rising temperatures, currently, in Nigeria, the likely impacts of the phenomena on the health of Nigerians, their environment and indeed on the global environment. The paper also carried out a survey of the multi-disciplinary research findings and ongoing debates in the intellectual fora on climate change and global warming. Based on the above, the following recommendations are made.

\section{RECOMMENDATIONS}

The following are recommendations drawn from various experts and institutions which make the following recommendations more compelling:

1. That Nigerian and indeed the global community are urged to drink more water to stay hydrated and also do the following:

2. Avoid alcoholic and caffeinated beverages during this time.

3. Reduce the consumption of proteins rich foods (e.g. red meats) as they increase metabolic heat.

4. Feed on fresh fruits and vegetables that are better options.

5. Monitor the individual blood pressures to make sure one is in the normal range.

6. Take baths of water before going to bed each night.

7. There is urgent needs not to ignore the various scientific findings on the damages of global warming and climate change which can cause to man's health and his environment as this may lead to catastrophic consequences.

8. Nigerians and indeed the global community must understand that in man's interaction with nature, over time, global warming and climate change have become negative developments which mankind must adjust to live in the various environment.

9. "Technology - powered - new jobs and new industries though adding value to society, must maintain economic vitality and natural treasures - the forests, the water ways, the cropland, the snowcapped peaks the flora and the fauna must be protected, for that is how we will preserve our planet commanded to our care by God". 1

\footnotetext{
${ }^{1}$ http:// Putinru. Corn/news iteml3/072html.
} 